\title{
COMPARISON OF PHYSIOLOGICAL PARAMETERS IN CHILDREN UNDERGOING DENTAL TREATMENT UNDER GENERAL ANESTHESIA WITH PROPOFOL AND SEVOFLURANE - A RETROSPECTIVE COHORT STUDY
}

\author{
LAVANYA G ${ }^{1 *}$, DEEPA GURUNATHAN ${ }^{1}$, NAVANEETHA KRISHNAN ${ }^{2}$
}

${ }^{1}$ Department of Pediatric and Preventive Dentistry, Saveetha Dental College, Chennai, Tamil Nadu, India. ${ }^{2}$ Department of Anesthesiology, Saveetha Medical College, Chennai, Tamil Nadu, India. E-mail: glaavuu@gmail.com

Received: 11 June 2017, Revised and Accepted: 20 July 2017

ABSTRACT

Objective: The present study was conducted to evaluate the effect of these drugs on the blood pressure (BP) and pulse rate during induction of anesthesia in children undergoing full mouth rehabilitation.

Methods: Data were collected from the records maintained for the children $<6$ years who underwent full mouth rehabilitation under general anesthesia (GA). The drugs used for induction, the changes seen in the BP, pulse rate were recorded. Statistical analysis was done using Mann-Whitney test with $\mathrm{p}<0.05$, significant.

Results: Of 64 children treated under GA, 31 children were induced with propofol and by sevoflurane in the remaining 33 children. The induction time with $2 \mathrm{mg} / \mathrm{kg}$ dosage of propofol was approximately 12 seconds while it was variable with $8 \%$ sevoflurane. The mean systolic and diastolic BP and pulse rate were found to be within the normal levels under both the drugs.

Conclusion: In children, sevoflurane and propofol can be safely used for inducing anaesthesia.

Keywords: Blood pressure, Children, Induction, Propofol, Pulse rate, Sevoflurane.

(c) 2017 The Authors. Published by Innovare Academic Sciences Pvt Ltd. This is an open access article under the CC BY license (http://creativecommons. org/licenses/by/4. 0/) DOI: http://dx.doi.org/10.22159/ajpcr.2017.v10i11.20599

\section{INTRODUCTION}

According to the American Society of Anesthesiologists, general anesthesia (GA) is a transient loss of consciousness induced by drugs where the patient is unable to independently maintain the airway and often requires assistance. Cardiovascular function may also be impaired. Treating pediatric patients under GA for the invasive and minor surgical procedures have markedly increased since the past decade, of which dental treatments under GA have a major contribution. The goals of treating patients under anesthesia include (a) patients safety and welfare, (b) reduced physical discomfort and pain, (c) reduce the anxiety level, and (d) control the movements to ensure safe completion of the procedure. These goals can be best achieved by selecting the appropriate drugs [1]. Various drugs used for inducing anesthesia broadly fall into two categories - Inhalational anesthetics and intravenous agents [2]. Isoflurane, desflurane, and sevoflurane are the commonly used potent inhalational agents. The commonly used intravenous agents include barbiturates, ketamine, propofol, and etomidate. A lot of studies have been conducted with newer anesthetic agents in animals $[3,4]$. Still propofol is considered as the choice of drug for induction by anesthetist though it is expensive [5]. Monitoring of the anesthetized patient is as important as selection and administration of the drug. Monitoring of the anesthetized patient is a continual process throughout the anesthetic event from pre-medication to full recovery. The parameters assessed throughout the anesthetic procedures include respiratory rate, oxygen saturation level, heart rate, pulse rate, arterial blood pressure (BP), and body temperature. There is a lack of evidence in the literature comparing the influence of the drugs used for induction of anesthesia on the physiological parameters in children treated under GA for dental procedures. The aim of this study was to evaluate the physiological parameters (pulse rate and arterial BP) in children under various drugs - Sevoflurane and propofol during full mouth rehabilitation under GA.

\section{METHODS}

The study was designed as a 1 year retrospective cohort study using the records of the patients treated under GA for full mouth rehabilitation from January to December 2015 in a dental institution in Chennai. The study was conducted after obtaining approval from the Institutional Review Board (STP/SDMDS2015PED42). A total of 64 children of age $<6$ years treated under GA for full mouth rehabilitation from January to December 2015 were included in this study. Sample size was based on the number of patients treated under GA in the year 2015. Due to the retrospective design of the study, sample size calculation based on statistical considerations was not applicable. The data were collected from the records maintained for the children undergoing full mouth rehabilitation under GA. Propofol and sevoflurane were the two drugs used for inducing anesthesia. The physiological parameter which includes the arterial BP and pulse rate was recorded at every 5 minutes throughout the procedure and was noted on the information sheet. Statistical analyses were done using Mann-Whitney test with $\mathrm{p}<0.05$ was considered to be statistically significant.

\section{RESULTS}

Of 64 children treated under GA, propofol was used to induce anesthesia in 31 children and for the remaining 33 children sevoflurane was used for induction of anesthesia. The mean dosage of propofol used was $29.84 \pm 9.873$ and the mean dosage of sevoflurane used was $4.79 \pm 3.890$. The descriptive statistics of the drugs used in children for 1 year is given in Table 1.

The descriptive statistics of the physiological parameters of the children undergoing full mouth rehabilitation under GA is tabulated in Table 2.

In the patients, on whom propofol was used for induction of anesthesia, the mean systolic pressure was $30.82 \mathrm{~mm} \mathrm{Hg}$ and the mean diastolic 
Table 1: Descriptive statistics of the drugs

\begin{tabular}{lll}
\hline Drug & n & Mean dosage \\
\hline Propofol & 31 & $29.84 \pm 9.873$ \\
Sevoflurane & 33 & $4.79 \pm 3.890$ \\
Succinylcholine & 64 & $24.54 \pm 6.240$ \\
\hline
\end{tabular}

Table 2: Descriptive statistics of the physiological parameters

\begin{tabular}{lll}
\hline Parameters & $\mathbf{n}$ & Mean \pm SD \\
\hline Systolic & 64 & $106.17 \pm 15.345$ \\
Diastolic & 64 & $60.06 \pm 10.844$ \\
Pulse rate & 64 & $137.12 \pm 19.548$ \\
\hline SD: Standard deviation & &
\end{tabular}

Table 3: Relationship of the drugs with the physiological parameters

\begin{tabular}{llll}
\hline Parameters & Group 1 propofol & Group 2 sevoflurane & p value \\
\hline $\mathrm{n}$ & 31 & 33 & \\
Systolic & 30.82 & 34.08 & 0.484 \\
Diastolic & 28.87 & 35.91 & 0.130 \\
Pulse rate & 30.68 & 34.21 & 0.448 \\
\hline
\end{tabular}

pressure was $28.87 \mathrm{~mm} \mathrm{Hg}$. The pulse rate in patient's induced using propofol was found to be 30.68 . The mean systolic and diastolic pressures were found to be $34.08 \mathrm{~mm} \mathrm{Hg}$ and $35.91 \mathrm{~mm} \mathrm{Hg}$, respectively, when anesthesia was induced using sevoflurane. The relationship of the drugs used and the physiological parameters is tabulated in Table 3. In the present study, there is no statistically significant relationship between the drugs used and their effects on the physiological parameters - arterial pressure and pulse rate.

\section{DISCUSSION}

Despite the availability of wide range of anesthetic drugs, sevoflurane is found to be useful in inducing anesthesia in children [6]. Anesthetic doses of propofol are successfully used for induction of anesthesia in anxious children facilitating the dental treatment [7]. The question regarding which anesthetic agent - propofol or sevoflurane is safe in children is still controversial. Hence, in the present study, we extracted the records of the children treated under GA with propofol and sevoflurane induction and compared their effects on the physiological parameters such as BP and pulse rate during the anesthetic procedure. In the present study, out of 64 children treated under GA, propofol was used in 31 children and sevoflurane in the remaining 33 children. $2 \mathrm{mg} / \mathrm{kg}$ body weight of propofol and $8 \%$ sevoflurane was used for induction of anesthesia in children. The induction time with propofol was approximately 12 seconds while it was variable with sevoflurane. Various studies comparing sevoflurane and propofol have been reported in adults. It has been found that the induction time was shorter with propofol compared to sevoflurane, which was in concordance to the present study and the emergence time was shorter with sevoflurane than propofol [8]. With regard to the physiological parameters, the minimum acceptable BP is $80 / 40$ in children. In our study, the mean systolic BP was found to be within the normal levels under both the drugs. No major commendable change was noted in the pulse rate when induction was done using sevoflurane and propofol respectively. No statistically significant association was noted with the drugs used and the changes in the parameters. Post-operative nausea and vomiting were not seen in both the groups in our study. This result is similar to the results obtained in another study where the postoperative nausea, vomiting, pain, and discomfort scores were similar between both the groups [8]. The reason could be because the children are at lower risk group and also for the dental procedures to prevent drying and inflammation of the oral mucosa dexamethasone is injected which has antiemetic properties. In addition, an antiemetic drug is given as pre-medication agent. In children induced with propofol, the anesthetic drug itself has antiemetic properties. However, it has been reported that the post-operative nausea and vomiting rate with propofol induction in children $\geq 3$ years are twice as high as adults and are rare in children $<2$ years of age [9]. Although sevoflurane and propofol had similar effects, propofol is still considered as the preferred anesthetic agent for induction due to its favorable induction characteristics, high patient satisfaction and less frequent incidence in post-operative nausea and vomiting [10].

\section{CONCLUSION}

Sevoflurane and propofol, being inhalatory and intravenous drugs, respectively, have similar effects on the BP and pulse rate when used for inducing anesthesia. Both of these drugs can be effectively and efficiently used in children during full mouth rehabilitation under GA.

\section{REFERENCES}

1. Cote CJ, Wilson S. Guidelines for monitoring and management of pediatric patients before, during and after sedation for diagnostic and therapeutic procedures: An update 2016. Pediatr 2016;138:e1-31.

2. Alwardt CM, Redford D, Larson DF. General anesthesia in cardiac surgery: A review of drugs and practices. J Extra Corpor Technol 2005;37:227-35.

3. Yakubu JM, Abdullahi A, Bhagavandas M, Onifade KI. Effect of time influence on physiological parameters following ketamine and diazepam administration in cats. Int J Pharm Pharm Sci 2015;7:363-6.

4. Akioye AA, Ojiaka HN, Samuel ES. Xylazine-ketamine anaesthesia; comparitive studies in male and female cane rats. Int J Pharm Pharm Sci 2017:9:52-5.

5. Tagliente TM. Pharmacoeconomics of propofol in anesthesia. Am J Health Syst Pharm 1997;54:1953-62.

6. Kim SO, Kim YJ, Hyun HK, Koo YS, Shin TJ. Deep sedation with sevoflurane inhalation via a nasal hood for brief dental procedures in pediatric patients. Pediatr Emerg Care 2013;29:926-8.

7. Hosey MT. Propofol intravenous consious sedation for anxious children in a specialist paediatric dentistry unit. Int J Paediatric Dent 2004:14:2-8.

8. Jellish WS, Lien CA, Fontenot HJ, Hall R. The comparative effects of sevoflurane versus propofol in the induction and maintenance of anesthesia in adult patients. Anesth Analg 1996;82:479-85.

9. Lerman J. Surgical and patient factors involved in postoperative nausea and vomiting. Br J Anaesth 1992;69 7 Suppl 1:24S-32.

10. Joo HS, Perks WJ. Sevoflurane versus propofol for anesthetic induction: A meta-analysis. Anesth Analg 2000;91:213-9. 